\title{
The Rotterdam Scan Study: design update 2016 and main findings
}

\author{
M. Arfan Ikram ${ }^{1,2,3} \cdot$ Aad van der Lugt $^{2}$ • Wiro J. Niessen ${ }^{4,5} \cdot$ Peter J. Koudstaal $^{3}$ • \\ Gabriel P. Krestin ${ }^{2} \cdot$ Albert Hofman $^{1} \cdot$ Daniel Bos $^{1,2} \cdot$ Meike W. Vernooij $^{1,2}$
}

Received: 30 September 2015 / Accepted: 25 November 2015/Published online: 9 December 2015

(C) The Author(s) 2015. This article is published with open access at Springerlink.com

\begin{abstract}
Imaging plays an essential role in research on neurological diseases in the elderly. The Rotterdam Scan Study was initiated as part of the ongoing Rotterdam Study with the aim to elucidate the causes of neurological disease by performing imaging of the brain in a prospective population-based setting. Initially, in 1995 and 1999, random subsamples of participants from the Rotterdam Study underwent neuroimaging, whereas from 2005 onwards MRI has been implemented into the core protocol of the Rotterdam Study. In this paper, we discuss the background and rationale of the Rotterdam Scan Study. Moreover, we describe the imaging protocol, image post-processing techniques, and the main findings to date. Finally, we provide recommendations for future research, which will also be topics of investigation in the Rotterdam Scan Study.
\end{abstract}

Keywords Epidemiology $\cdot$ Population-based $\cdot$ Risk factors $\cdot$ Neuroimaging $\cdot$ Cohort study $\cdot$ Dementia $\cdot$ Stroke . Alzheimer's disease · Microbleeds · White matter lesions .

M. Arfan Ikram

m.a.ikram@erasmusmc.nl

1 Department of Epidemiology, Erasmus MC University Medical Center, P.O. Box 2040, 3000 CA Rotterdam, The Netherlands

2 Department of Radiology, Erasmus MC University Medical Center, Rotterdam, The Netherlands

3 Department of Neurology, Erasmus MC University Medical Center, Rotterdam, The Netherlands

4 Biomedical Imaging Group Rotterdam, Erasmus MC University Medical Center, Rotterdam, The Netherlands

5 Faculty of Applied Sciences, Delft University of Technology, Delft, The Netherlands
Infarcts - Cerebral blood flow - Diffusion tensor imaging · Genetics

\section{Introduction}

Neurologic diseases in the elderly, such as dementia and stroke, will pose an ever increasing burden on societies over the next couple of decades [1-4]. Yet, effective therapeutic or preventive strategies are still lacking. In order to develop such strategies, knowledge on the etiology of these diseases is crucial. An important feature of neurodegenerative diseases is that structural and functional brain changes may be already present years before clinical onset and can be visualized using magnetic resonance imaging (MRI) [5-10].

Realizing this potential benefit, already in the 1990s, neuroimaging was implemented in several populationbased studies to study the preclinical brain changes that ultimately lead to or may indicate an increased risk of developing clinically manifest diseases, such as dementia and stroke [7, 11-19]. However, in most of these studies neuroimaging was only performed in a subset of the population, resulting in limited sample sizes. More importantly, during the last two decades MR imaging has undergone huge improvements in hardware and software leading to higher field strengths, higher resolution, shorter scanning times, and more sensitive sequences. In addition, digital image analysis techniques have led to a new field of research aimed at automating and increasing through-put of image processing for better visualization and quantification of imaging findings. Taken together, these developments now allow for performing neuroimaging in larger sample sizes and using state-of-the-art imaging and processing techniques. In turn, this has paved the way for more in 
depth and thorough investigation of (more subtle) brain changes that can lead to neurological diseases.

It was in this light, that in 1995 the Rotterdam Scan Study was initiated to investigate risk factors and risk indicators of neurological diseases in the elderly using MR imaging to visualize the underlying brain changes and brain pathology. In 1995 and 1999, random subsamples of Rotterdam Study participants underwent neuroimaging in clinical scanners. From 2005 onwards, the Rotterdam Scan Study has been embedded within the core protocol of the Rotterdam Study [20], and a dedicated research scanner was installed in the Rotterdam Study research center.

In the current paper, we provide a general outline of the study population, scanning protocol, image post-processing and a discussion of the main findings of the Rotterdam Scan Study, with the main focus on the period from 2005 to 2015.

\section{Design and study population}

The source population of the Rotterdam Scan Study originates from the Rotterdam Study [21], a population-based study in the Netherlands that aims to investigate causes and determinants of chronic diseases in the elderly. The Rotterdam Study (RS I) was initiated in 1990 with 7983 participants aged 55 years and over, who were interviewed and underwent physical exam at baseline and during follow-up visits every 3-4 years. In 2000, the cohort was extended with 3011 persons (RS II), who were aged 55 and over at that time. In 2006 the cohort was further extended with 3932 persons aged 45 years and over (RS III). The whole cohort undergoes re-examinations every 3-4 years. The total Rotterdam Study population encompasses 14,926 persons.

Figure 1 shows an overview of the various Rotterdam Study cohorts, the time of their (re-)examination visits, and the implementation of MRI-scanning in the core protocol of the Rotterdam Study in 2005. Initially, we invited random persons from the second visit of RS II to undergo MRI. Subsequently, we have scanned all eligible and consenting participants from the first visit of RS III and fifth visit of RS I. Currently, persons from the fourth visit of RS II are undergoing scanning. Of all persons taking part in the Rotterdam Study, those with MRI contra-indications are considered not eligible for the Rotterdam Scan Study. Furthermore, persons suffering from claustrophobia are also not included. Because the throughput of performing MR imaging has been higher than that of the Rotterdam Study (56 MRI slots per week versus 36 slots for regular study center visits), we were able to invite additional subsets for re-scanning. As such, we re-invited participants from RS I in 2006, RS II in 2008, and RS III in 2010 outside their regular visits for the Rotterdam Study. As a result, some of the participants are already undergoing their fourth MRI-exam.

Therefore, as of July 2015 , a total of 12,174 brain MRscans have been obtained on the research scanner in over 5800 individuals.

\section{Scan protocol}

In 2005, a 1.5T MRI unit (General Electric Healthcare, Milwaukee, USA, software version 11x), dedicated to the Rotterdam Scan Study, was installed in the Rotterdam Study research center. Besides the possibility of high throughput image acquisition, this enabled us to leave acquisition parameters unchanged by excluding software or hardware upgrades in order to ensure data stability and comparability over time. The MRI unit was fitted with a dedicated 8-channel head coil (best coil configuration available at time of installation) and the possibility for parallel imaging using the array spatial sensitivity encoding technique (ASSET).

Maximum total examination time (from arrival of one participant in the MRI suite until the next) was initially set at $45 \mathrm{~min}$, in order to accommodate the MRI acquisition into the generic workflow of the Rotterdam Study. Later, this became $50 \mathrm{~min}$ due to the addition of a resting-state functional MRI sequence (rs-fMRI), which is discussed in detail below.

In the current scan-protocol we carefully balanced the restrictions of time, costs and inconvenience for the participants with the relevance and quality of the acquired imaging data. To ensure participant compliance and reproducible image quality (reduce motion artefacts) an acquisition limit of 6 min per sequence was chosen.

To facilitate easier applicability of the current MRI protocol by radiology technicians, we chose to use the standard brain imaging package delivered by the system manufacturer instead of custom developed sequences.

The MRI sequences were chosen based on the primary variables of interest, i.e.:

1. quantitative measures of brain tissue volumes and volumes of various neurostructures (e.g. hippocampus)

2. quantitative assessment of white matter lesions (WMLs),

3. qualitative assessment of brain infarcts (lacunar and cortical) and microbleeds,

4. quantitative assessment of white matter microstructural integrity and connectivity,

5. quantitative assessment of total cerebral blood flow,

6. quantitative assessment of functional brain networks.

In designing the protocol, we tried to meet both the time constraint and the contrast and resolution requirements. 


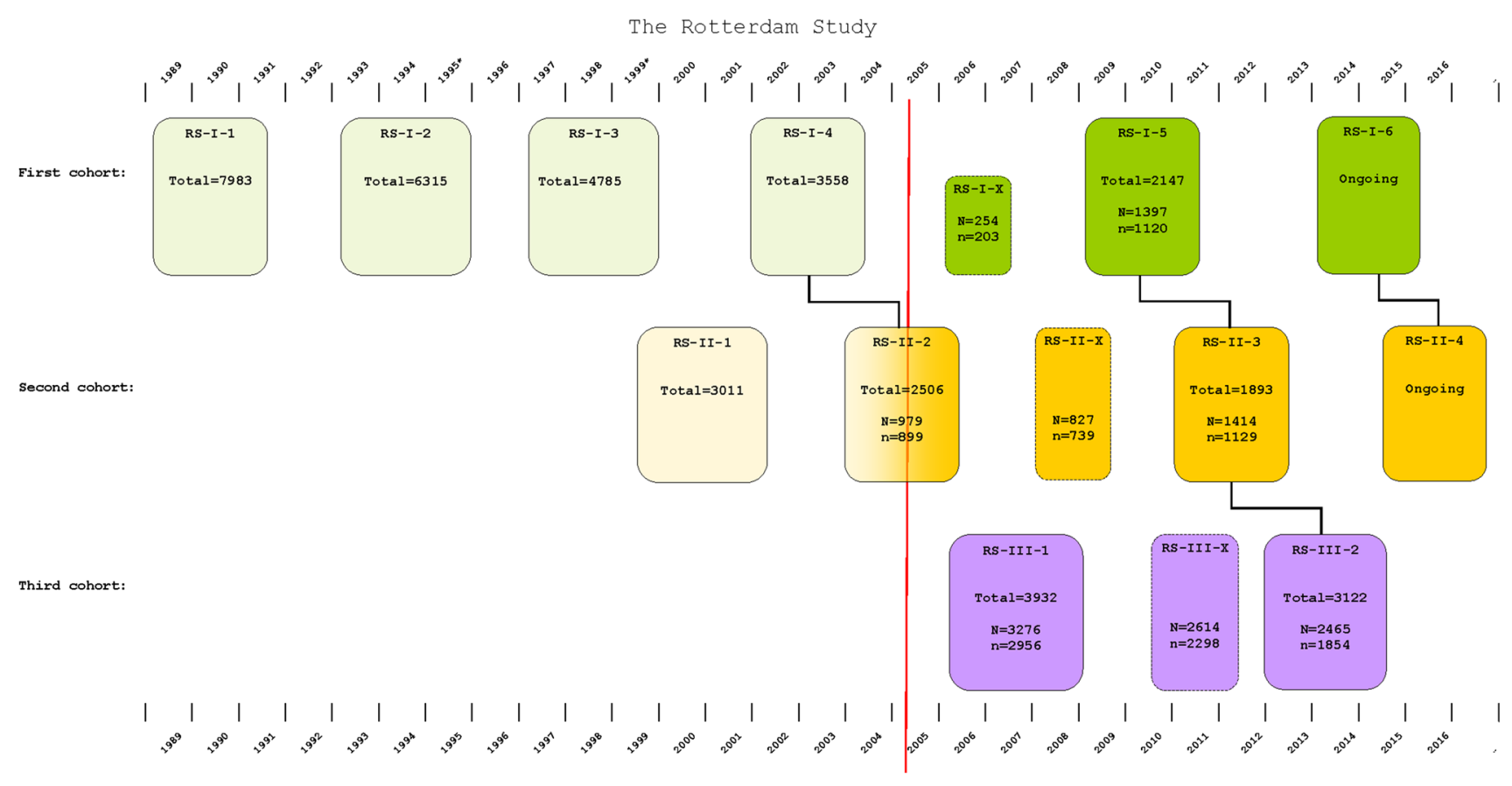

Fig. 1 Overview of the sub-cohorts and examination visits of the Rotterdam Study, and imaging visits of the Rotterdam Scan Study. Boxes indicate examination visits of the three cohorts of the Rotterdam Study. Boxes with solid colors indicate visits, during which MRI imaging was conducted as part of the core protocol. Examination visits indicated with an ' $\mathrm{X}$ ' indicate extra visits during which only MRI was performed. The red vertical line indicates the implementation of MRI on site in the core protocol of the Rotterdam

When possible, we preferred $3 \mathrm{D}$ over $2 \mathrm{D}$ sequences because of higher signal-to-noise ratio (SNR), which enables the acquisition of smaller voxel sizes. Yet, acquisition time, sensitivity to motion and blurring artefacts did not allow 3D acquisition in all sequences. For each sequence, we adjusted the imaging parameters during optimization procedures to obtain a specific target resolution with adequate SNR $(\geq 25)$ for tissues in the center of the brain while scan time was limited to 6 min for each sequence.

Since mid-2011, the structural MRI protocol has been extended with a resting-state functional MRI (rs-fMRI) sequence, further described below. Despite the original aim to limit scan time to 6 min per sequence, this functional scan requires $8 \mathrm{~min}$ to obtain adequate resting-state data.

The resulting protocol is presented in Table 1 with all the relevant imaging parameters and the execution order listed. The protocol starts with a three-plane localizer, executed with the shimming option enabled. For subsequent sequences shimming is turned off to accelerate receiver adjustments. Morphological imaging is performed with T1-weighted (T1w), proton density-weighted (PDw) and fluid-attenuated inversion recovery (FLAIR) sequences. The combination of different MR contrasts provided
Study. In 1995 and 1999 (indicated with *) 567 persons underwent MRI as part of the Rotterdam Scan Study outside the core protocol of the Rotterdam Study. 'Total' indicates the total number of persons taking part in that Rotterdam Study examination visit. 'N' indicates the number of persons that were eligible (no MRI contra-indications and no claustrophobia) and invited to take part in the Rotterdam Scan Study. ' $n$ ' indicates the number of persons that underwent brain MRI in the Rotterdam Scan Study

by these sequences can be used for automated segmentation of brain tissue and WMLs (see section on processing). For the purpose of segmentation, the T1w scan is acquired in 3D at high in-plane resolution and with thin slices (voxel size $<1 \mathrm{~mm} 3$ ). A 3D T2*-weighted gradient-recalled echo (GRE) scan is used to image cerebral microbleeds. For this sequence a TE $>30 \mathrm{~ms}$ was selected to obtain stronger T2*-weighting. For registration purposes, the same slice thickness with a lower in-plane resolution as compared to the 3D T1w scan is used. Parallel imaging is applied for this sequence to stay within the 6 min scan time limit.

Diffusion tensor imaging (DTI) is used to quantitatively assess white matter microstructural integrity [22, 23]. For this 2D DTI scan, we use an echo planar imaging (EPI) readout with gradients $\left(b=1000 \mathrm{~s} / \mathrm{mm}^{2}\right)$ applied in 25 directions $[22,23]$. The $\mathrm{b}=0 \mathrm{~s} / \mathrm{mm}^{2}$ image is collected with NEX $=3$. The number of gradient directions, i.e. 25 , was chosen to best fit the optimized protocol by Jones et al. $[22,23]$ whilst remaining within time limits and maximum number of slices permitted by the scanner. To minimize geometrical distortions, the number of frequency encoding points was set to 64 and parallel imaging was applied with an acceleration factor of 2, with an imaging matrix of $64 \times 96$, providing a voxel size of $3.3 \times 2.2 \times 3.5 \mathrm{~mm}^{3}$. 


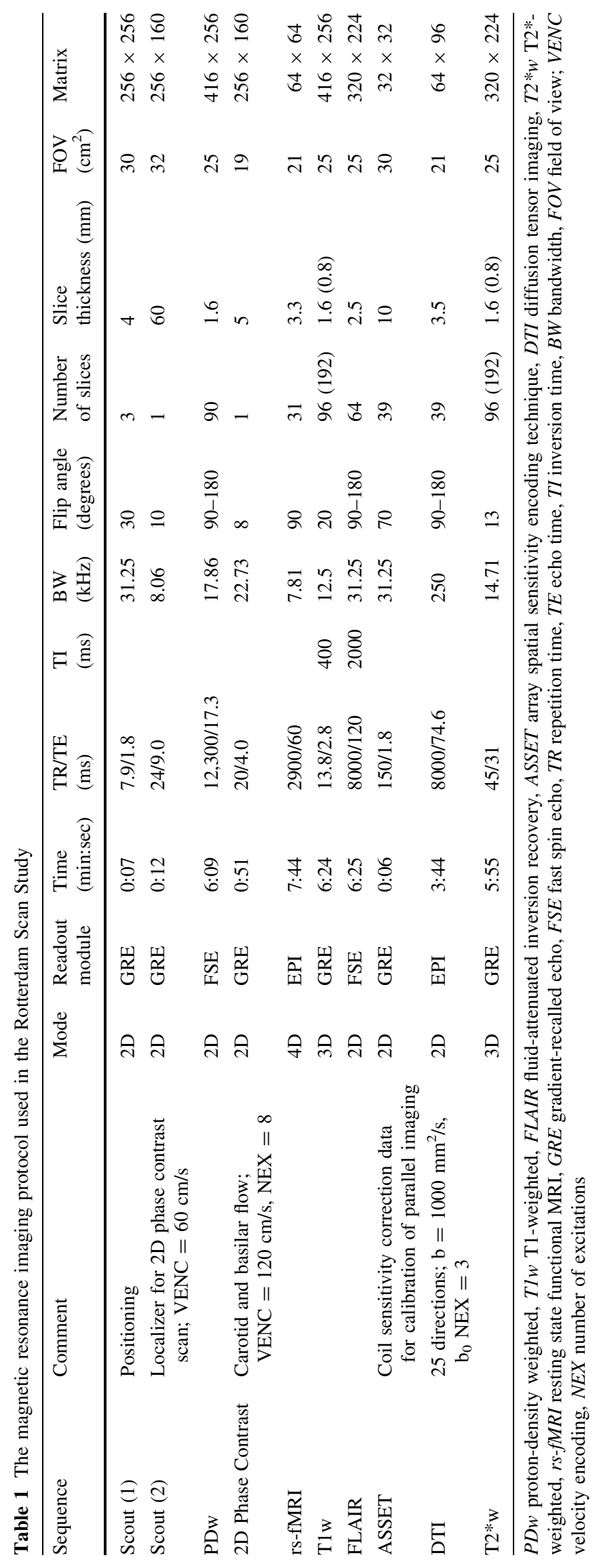


An ungated 2D GRE phase contrast flow measurement is applied for assessment of total cerebral blood flow [24], which has shown to be fast and accurate [24]. A 2D thick slab projection phase contrast angiographic localizer $(60 \mathrm{~mm}$ thick, velocity encoding $(\mathrm{VENC})=60 \mathrm{~cm} / \mathrm{sec})$ is positioned sagittally to determine the location of the carotid and basilar arteries. Next a thin slice perpendicular to all three vessels at the level of the precavernous internal carotid artery is positioned (VENC $=120 \mathrm{~cm} / \mathrm{s}$, slice thickness $5 \mathrm{~mm}, \mathrm{NEX}=8$ ). Flow velocity data can be calculated from the phase difference images as described before [24]. For rs-fMRI, subjects are instructed to lie still with their eyes open, and not to fall asleep. T2*-weighted echo planar images (EPIs) are acquired with $3.3 \mathrm{~mm}$ isotropic voxels, and a total of one-hundred sixty volumes.

Figure 2 illustrates an example of the different sequences acquired in the final protocol. The sequence acquisition order was chosen in a way to provide adequate reconstruction speeds and to eliminate delays. The 3D T2*w GRE scan was the last sequence executed in the protocol pipeline because of the long reconstruction time necessary for parallel imaging and the resulting lag time in scan execution.

For quality check, a daily quality assessment (measuring transmit gain, center frequency and SNR) is performed by technicians using a phantom. Additionally, weekly measurements of echo-planar stability, isocenter reliability and accuracy of absolute scaling along the cardinal axes $(\mathrm{x}, \mathrm{y}, \mathrm{z})$ are performed. Regular scanner maintenance is performed by the manufacturer and results are filed in a log.

Furthermore, interscan reproducibility measurements have been performed by re-inviting study participants ( $\mathrm{n}=20-30)$ within on average 2 weeks after initial examination for repeat MRI.

\section{Image processing}

Within the context of the Rotterdam Scan Study, a standardized image analysis workflow is being developed, validated and applied to all imaging data, to enable the objective, accurate, and reproducible extraction of relevant parameters describing brain anatomy, possible brain pathologies, and structural and functional brain connectivity from multispectral MRI data. In the following paragraphs, we briefly describe the different quantitative image analysis methods that have been developed and/or employed within the Rotterdam Scan Study.

\section{Image pre-processing}

Prior to analysis, a number of pre-processing steps are performed. For multispectral image analysis, the different scans are spatially registered using rigid registration. Subsequently, the brain is extracted from the scan. Hereto a manually segmented brain mask-which excludes among other things, the cerebellum, the eyes, and the skull-is non-rigidly registered to the $\mathrm{T} 1$-weighted image using Elastix [25].

Finally, scans are corrected for intensity non-uniformity using the N3 method [26]; non-uniformity correction is carried out within the brain mask.

\section{Brain tissue segmentation}

Automated brain tissue segmentation on MRI has received considerable attention [11, 27-32]. An important distinction that can be made is whether methods are supervised (i.e. they depend on annotated training data), or unsupervised. In the Rotterdam Scan Study, we use a supervised approach, based on k-nearest neighbour ( $\mathrm{kNN}$ ) segmentation. In $\mathrm{kNN}$ segmentation, image voxels are assigned labels (grey matter (GM), white matter (WM), cerebrospinal fluid (CSF) or background (BG)) based on the most similar voxels in the training data. Similarity here depends on the distance in normalized MR image intensities. We have both investigated segmentation based on T1w images, and multispectral MRI data (T1w and PDw images). Manual segmentations by two observers of six T1w datasets (the PDw dataset is implicitly segmented after rigid registration to the $\mathrm{T} 1 \mathrm{w}$ datasets), that include labels for GM, WM, CSF, and BG, were used as training data [27, 33]. This brain tissue segmentation method has been extensively evaluated within the context of the Rotterdam Scan Study, showing good accuracy and reproducibility [33, 34]. An example of the automated tissue segmentation is shown in Fig. 3.

To facilitate more regionalized analysis of total brain, WM and GM volumes, individual lobes have been segmented. This is achieved by non-rigidly registering a template image in which the lobes have been manually outlined [35-37]. Finally, T1-weighted MR images have been used to calculate subcortical structures and thickness of the cerebral cortex using a model-based automated procedure using Freesurfer image analysis suite (http://sur fer.nmr.mgh.harvard.edu/) [38, 39].

\section{White matter lesion classification}

The brain tissue segmentation methods described above have been complemented with WML segmentation [40]. Hereto, both the brain tissue segmentation, and the FLAIR image are used. In the brain tissue segmentation, possible WMLs are misclassified as GM with a ring of WM voxels. In the FLAIR image the WMLs are hyperintense. We therefore process the histogram from the FLAIR image 
Fig. 2 Depiction of the images acquired using the MRI protocol. First row: T1weighted (a), proton-densityweighted $(b)$, and fluid attenuated inversion recovery (c) images. Second row: $\mathrm{T} 2{ }^{*}$ weighted $(d)$ image, sagittal scout for the 2D phase contrast measurement $(e)$, and the resulting flow image $(f)$. Third row: example of an image acquired using diffusion weighted imaging $(g)$, map of fractional anisotropy $(h)$, map of mean diffusivity $(i)$, and restingstate functional MRI $(j)$

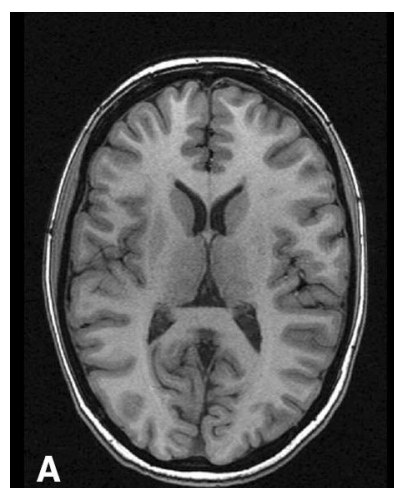

A
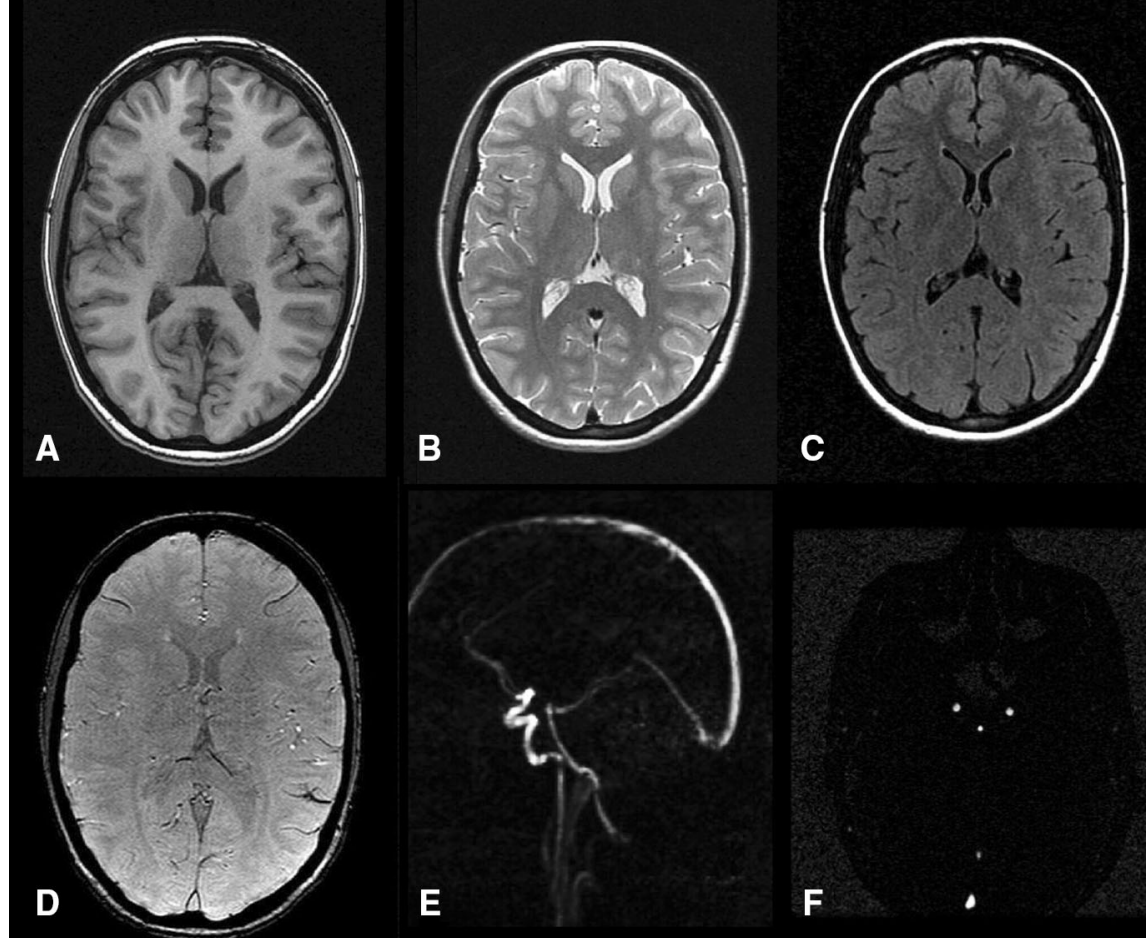

C

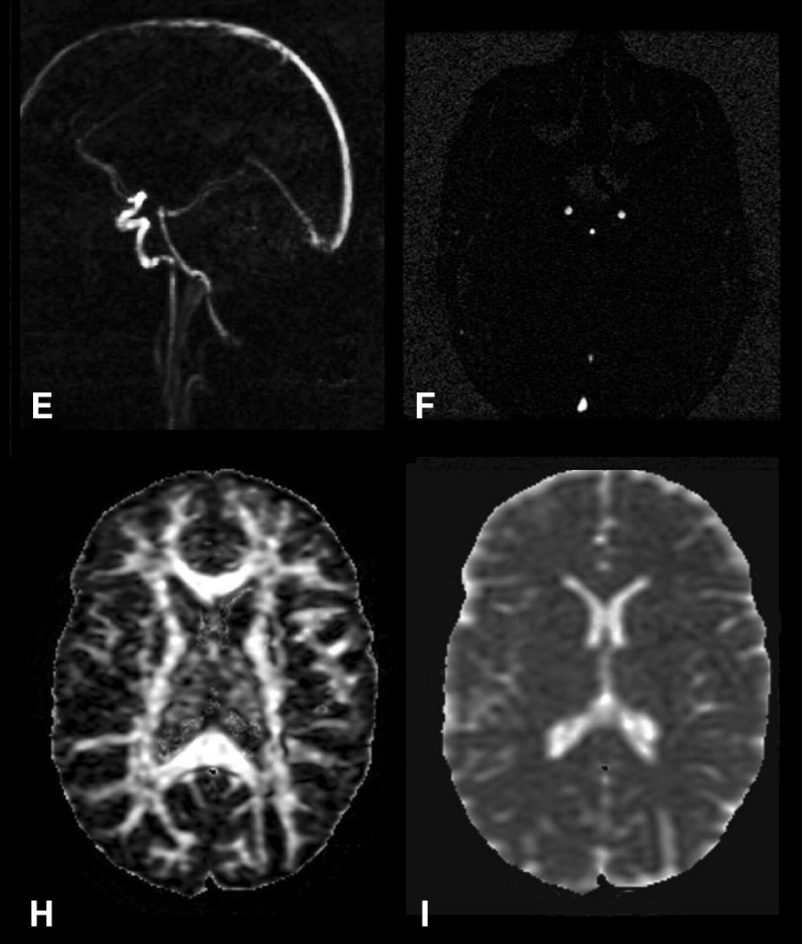

G

H

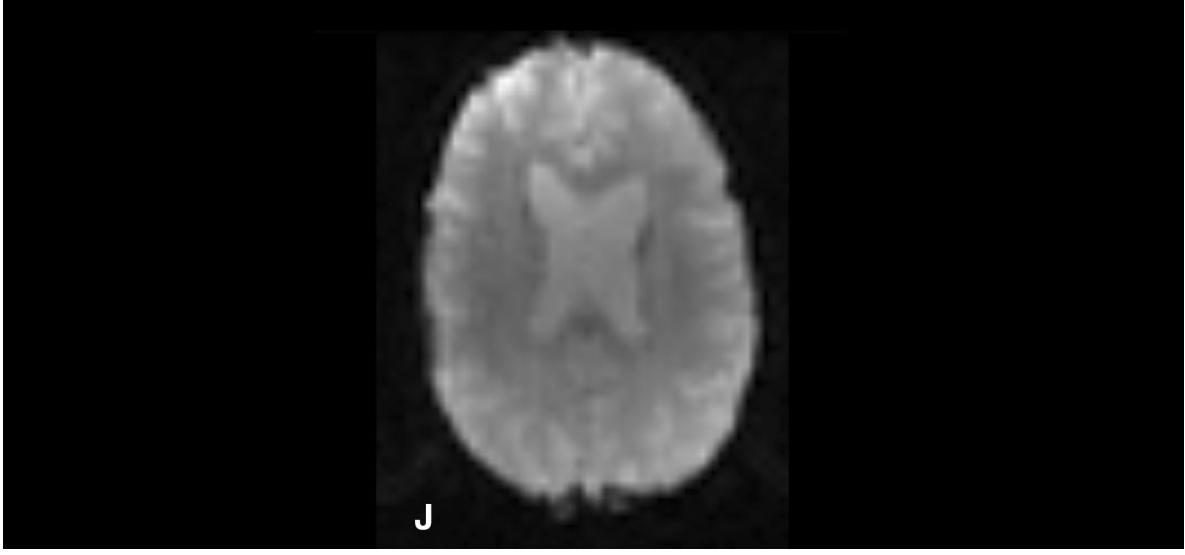

intensities of all voxels that are classified as GM, to estimate the mean and standard deviation of true GM voxels. Subsequently, WML voxels are extracted by intensity thresholding, where the threshold depends on the estimated GM distribution. False positives are removed by excluding voxels which are not sufficiently connected to the white matter. The different parameters (intensity threshold, and quantitative definition of not being sufficiently connected) have been optimized on a large reference dataset. The method has been quantitatively evaluated [40] and has 


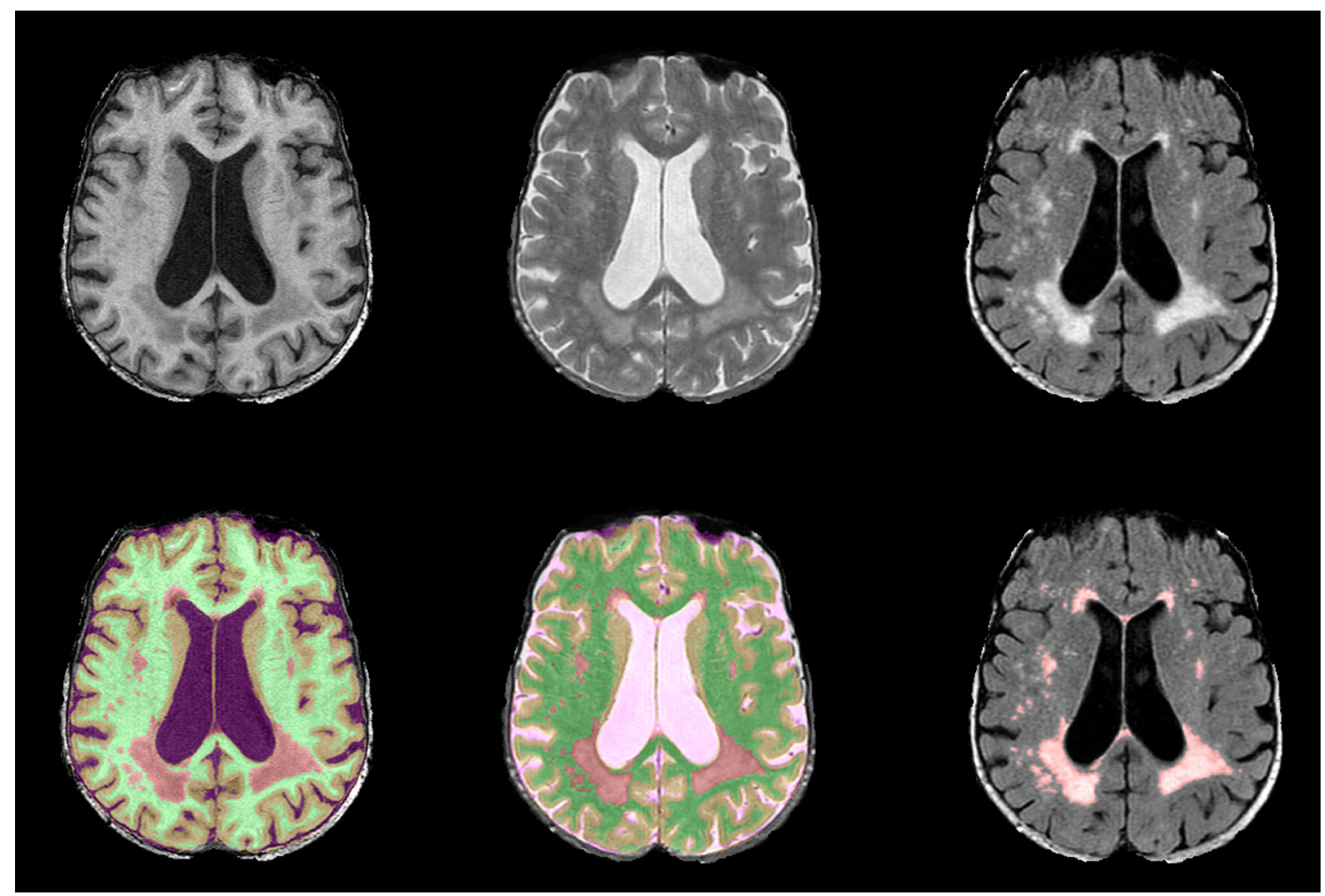

Fig. 3 Example of brain tissue segmentation. Left column T1weighted sequence with k-nearest neighbor based tissue segmentation into grey matter (orange), white matter (green), cerebrospinal fluid (purple), and white matter lesions ( $r e d$ ). Middle column: Proton-

successfully been applied to the whole cohort [41]. Visual inspection of the results indicates that the method is robust, with approximately only $4 \%$ of the scans containing false positive or false negative WMLs. Figure 3 demonstrates the automated WML segmentation result.

\section{Brain structure segmentation and shape analysis}

Within the Rotterdam Scan Study, we have developed a graph cut framework for neurostructure segmentation [42] combining atlas registration and statistical models of image appearance [43], which currently has been implemented for hippocampus segmentation. The developed framework utilizes twenty manually outlined hippocampi (atlases) [44], which are used both for atlas registration, and for training the statistical image appearance models. The twenty atlases are non-rigidly registered to an image to be segmented, after which by averaging a spatial probability map is obtained which indicates the likeliness of a voxel to belong to the hippocampus. Within a graph cut framework, this information is complemented by the likeliness that a voxel is part of the hippocampus based on intensity information, for obtaining a segmentation. The method has been shown to improve on existing manual hippocampus density weighted sequence with similar tissue segmentation. Right column FLAIR-sequence with white matter lesion segmentation (pink)

segmentation techniques [43], and has been applied to a number of studies $[45,46]$. Recently, we have extended the hippocampus method to also include more informative appearance models [47]. The graph cut framework developed for hippocampus segmentation has additionally been used for ventricle segmentation [48], and segmentation of the cerebellum [49, 50].

Based on the hippocampus segmentation, we also have developed a method to quantify hippocampal shape, and demonstrated that the combination of hippocampal volume and hippocampal shape performed better on the prediction of dementia than when just using volume [51].

\section{Diffusion tensor imaging (DTI): global and tract- based analysis}

DTI enables measurement of the microstructural integrity of white matter. Within the Rotterdam Scan Study, a number of image analysis techniques have been employed and developed for the analysis of DTI data. These include conventional global and regional analysis of DTI-derived measures such as Fractional Anisotropy (FA) and Mean Diffusivity (MD) [52], and tract-based analysis of FA and MD [53]. Global and regional analysis of FA and MD has 
been performed using the FSL toolbox [54], and consisted of Eddy current correction, head motion correction, skull stripping and tensor model fitting. As discussed below, DTI data were registered with the other imaging data to study relations between atrophy, WMLs, and DTI-derived measures.

Tract-based analysis of DTI enables a more localized comparison of FA and MD between groups. In the Rotterdam Scan Study, tract-based analysis has been achieved using tract-based spatial statistics (TBSS) [55] a technique that creates a common skeleton of the white matter tracts from a series of images, onto which for each individual the local maximum FA value is projected. This enables robust voxel-wise statistical analysis of the microstructural integrity of white matter across persons [53].

Since the projection step in TBSS may break topological consistency of the transformed images, we investigated whether the correspondence step in TBSS could be replaced by non-rigid registration. We evaluated performance of non-rigid registration to the conventional TBSS approach by performing tractography in native space and measuring the ability of the correspondence step in creating similarity in tractography results in 23 white matter structures in a common template space. It was shown that both non-rigid registration using Elastix [56] and FMRIB's Nonlinear Image Registration Tool (FNIRT) [57] outperformed the conventional TBSS analysis [58]. Furthermore, the approach enables the automatic analysis of diffusion MRI characteristics in 23 white matter tracts. An example of 23 automatically generated white matter tracts on a subject of the Rotterdam Scan Study is shown in Fig. 4.

\section{Diffusion tensor imaging: connectivity analysis}

Using deterministic or probabilistic tractography, DTI can also be used to study structural connectivity of the brain. In order to compare structural connectivity across persons in the Rotterdam Scan Study, we developed a novel framework, SAMSCo, which enables construction of weighted structural brain connectivity networks which can be effectively analyzed using statistical methods $[59,60]$. The weighted networks are obtained using a minimum cost path (mcp) method with an anisotropic local cost function based on the locally estimated diffusion tensor weighted images. Start and end regions of the mcp were defined by a Freesurfer segmentation [61, 62] of subcortical structures and cortical parcellation. Using a re-scan on 30 persons, good reproducibility of the connectivity maps was shown [34].

\section{Resting-state functional MRI: resting-state networks}

Preprocessing and analysis of rs-fMRI data is performed using the FMRIB software library (FSL, http://www.fmrib.

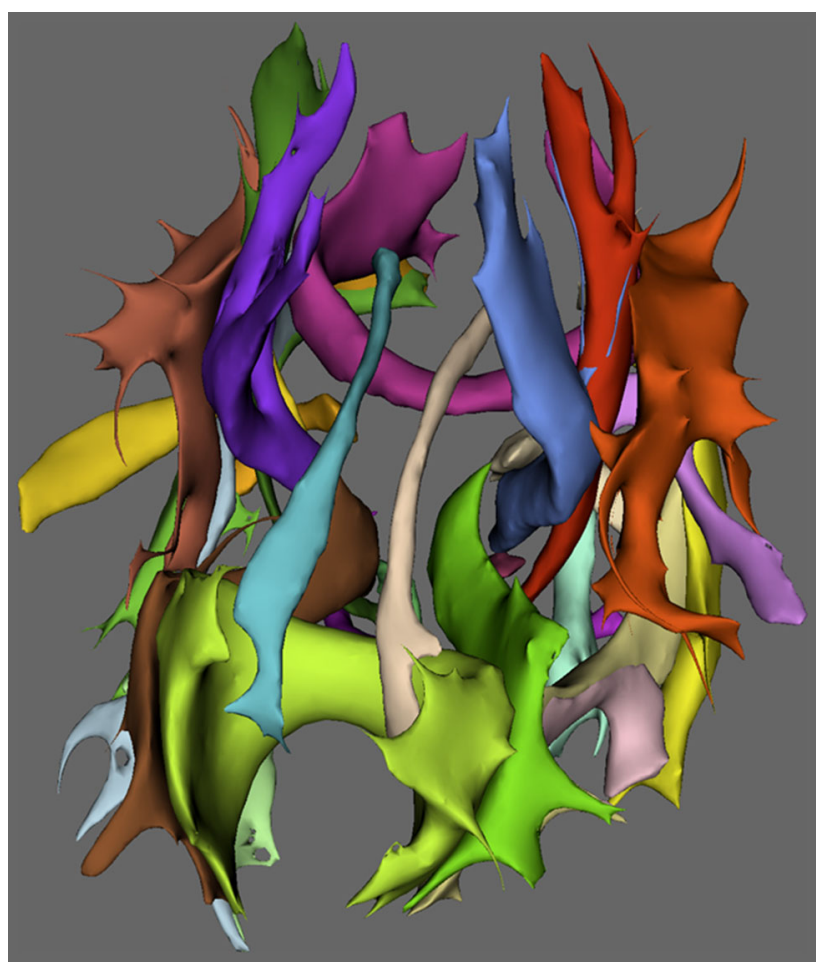

Fig. 4 Example of the automatic analysis of diffusion MRI characteristics in 23 white matter structures

ox.ac.uk/fsl/). Resting-state fMRI volumes are registered to the individual's structural scan and standard space using FNIRT [57]. A single-subject independent component analysis (ICA) [63] approach is used to decompose the acquired rs-fMRI data into various components of restingstate activity in each participant. Low-frequency drifts and motion components are handled with MCFLIRT and temporal filtering [63, 64]. Next, we applied an automatic component classification using FMRIB's ICA-based Xnoiseifier (FIX) for the discrimination between true signal versus noise components $[65,66]$. Next, using dual regression [67], spatial maps of various resting-state networks, including the default mode network, are derived for each participant. These maps are then used to generate measures of functional connectivity and clusters of activation within each network, and later also to make voxelbased comparisons.

\section{Visual ratings}

\section{Scan quality and incidental findings}

Each MRI scan that is acquired is visually examined by a research physician in the Rotterdam Scan Study. During this visual inspection, the MRI scan is rated for quality and the presence and severity of motion artefacts or signal 
inhomogeneity (for example due to metallic implants) is recorded. Furthermore, each scan is evaluated by trained research physicians for presence of incidental findings, i.e. abnormalities of potential clinical relevance that were previously unknown, that are unexpected and that are unrelated to the purpose of the scan [68, 69]. All potential findings are recorded in a database and are in a later stage evaluated by an experienced neuroradiologist. Referral of participants for further medical examination occurs in accordance with an expert-defined protocol [68].

\section{Visual check of automated processing performance}

Though post-processing for tissue segmentation and structure segmentation takes places fully automated and without user interaction, all end results are visually checked for performance. For example, small motion artefacts in the FLAIR sequence that do not necessitate exclusion of an MRI scan may interfere with WML segmentation and cause false positive lesions after automated segmentation; or brain masking may result in minimal inclusion of dura or skull. For manual inspection, a dedicated tool has been developed in MevisLab ${ }^{\circledR}$ enabling the visualization of the original scan with the image processing results (Fig. 5). Editing tools are available to adjust the segmentations if necessary. After visual inspection, manual editing of any errors is needed in less than $10 \%$ of scans, depending on the type of post-processing. Furthermore, less than $1 \%$ of scans are excluded based on artefacts that are only discovered after automated post-processing (for example motion or susceptibility artefacts in diffusion tensor images, which are not apparent in the raw unprocessed data).

\section{Cerebral small vessel disease}

Infarcts are rated on FLAIR, proton density-weighted, and T1-weighted sequences. Lacunar infarcts are defined as focal lesions $\geq 3 \mathrm{~mm}$ and $<15 \mathrm{~mm}$ in size with the same signal characteristics as CSF on all sequences, and (when located supratentorially) with a hyperintense rim on the FLAIR sequence [68]. Lesions $\geq 15 \mathrm{~mm}$ in size, but otherwise similar, are rated as subcortical infarcts. Infarcts showing involvement of cortical gray matter are classified as cortical infarcts. We further distinguish cortical infarcts into small and large infarcts based on their size [70].

All 3D T2* GRE scans are reviewed for the presence, number, and location of cerebral microbleeds. Microbleeds are defined as focal areas of very low signal intensity on T2*-weighted imaging that are not accompanied by evident signal abnormality on other structural sequences [71]. Microbleed location is categorized into one of three locations: lobar (cortical gray and subcortical or periventricular white matter), deep (deep gray matter: basal ganglia and thalamus, and the white matter of the corpus callosum, internal, external, and extreme capsule), and infratentorial (brainstem and cerebellum) [71]. Intraobserver and interobserver reliabilities for microbleed rating are very good $(\kappa=0.85-0.87[72])$ and review of the intial ratings by an experienced neuroradiologist yielded very high accordance as well [72].

\section{Virchow-Robin spaces}

Virchow-Robin spaces (VRS), or enlarged perivascular spaces, are primarily rated on the PDw-sequence according to a standardized protocol [73]. In short, VRS are identified by their linear, ovoid, or round shape depending on the slice direction and are considered dilated when their diameter is $\geq 1 \mathrm{~mm}$. VRS are assessed in 4 brain regions: the semioval center, the basal ganglia, the hippocampi, and the mesencephalon. Raters determine the amount of dilated VRS for each region, with a maximum of 20 per region. Because the semioval center and basal ganglia are visible on multiple slices, the rating is done on a single, predefined slice to decrease inter- and intrarater variability as described previously [73]. In the hippocampus and mesencephalon, all unique dilated VRS are counted. In 2013, we initiated the UNIVRSE (Uniform Neuro-Imaging of Virchow-Robin Spaces Enlargement) - consortium in order to investigate causes and consequences of VRS on a large scale [74].

\section{Main findings}

\section{Cerebral small vessel disease}

Already during the first round of MRI in the Rotterdam Study we learned that markers of ischemic small vessel disease such as WMLs and lacunar infarcts are highly prevalent in the elderly and that these relate to cardiovascular risk factors, such as hypertension or smoking [37, 7584]. In the MRI scans obtained from 2005 onwards, we confirmed this frequent occurrence of WML and infarcts in the elderly and extended the prevalence and volume estimates to the middle aged population [68]. Moreover, we found these cardiovascular risk factors to be associated with a thinner cortex of the brain [85]. In addition to studying the role of above-mentioned cardiovascular risk factors in the development of ischemic small vessel disease, we also directly investigated associations of atherosclerosis with these markers. Using arterial calcification (measured with computed tomography) as an established marker of atherosclerosis, we found atherosclerotic calcification in various vessel beds, but 


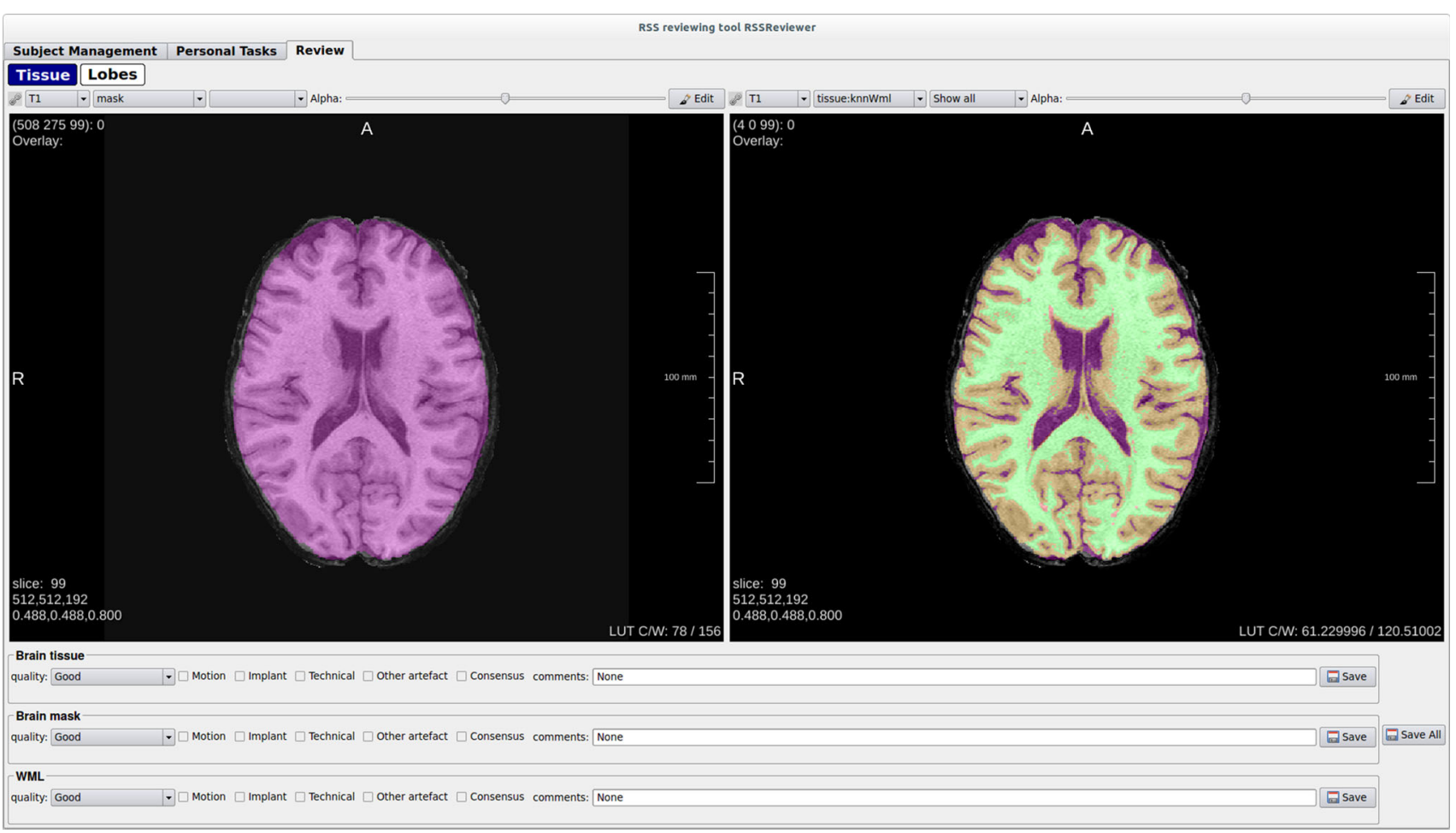

Fig. 5 Screenshot of the tool which enables the visualization of the original scan with the image processing results. On the left screen, the mask for total intracranial volume is shown. On the right screen the

especially in the intracranial vasculature, to be related to WMLs, lacunar infarcts, and brain atrophy [86, 87].

Besides focusing on its risk factors, we have also started investigating consequences of ischemic small vessel disease. In this light, we found that larger WML volumes and lacunar infarcts are associated with a higher risk of mortality [88], mild cognitive impairment [89], dementia [90], and a higher risk of stroke [91]. More recently, we found that larger WML volumes are associated with deterioration and incident impairment in daily functioning [92].

Besides the ischemic lesions in the context of cerebral small vessel disease, hemorrhagic lesions in the form of cerebral microbleeds have gained rapid interest [71]. To visualize cerebral microbleeds we use a dedicated 3D highresolution T2* GRE sequence, which we found to improve the detection of cerebral microbleeds considerably in comparison with a conventional MRI sequence [93]. When we applied this high-resolution sequence in larger groups of participants, we found that cerebral microbleeds are present in 1 in 5 persons over age of 60 and in over 1 in 3 in persons aged 80 years and older [72,94]. This prevalence is much higher than reported previously, which in part may be explained by the use of this dedicated MRI sequence. In a longitudinal study over an interval of 3-4 years, we found that $10 \%$ of persons developed new microbleeds rater can evaluate the tissue segmentation. In the lower panel, the rater can indicate the quality of the mask, the brain tissue segmentation and the white matter lesion segmentation

[95], and that this was highly dependent on the presence and amount of mircobleeds at baseline.

With regard to risk factors for microbleeds we consistently found that these vary according to the location of microbleeds in the brain. Cardiovascular risk factors and markers of ischemic small vessel disease are related to deep or infratentorial microbleeds, whilst $A P O E$ genotype relates to strictly lobar microbleeds $[72,94,95]$. This is indirect evidence that deep or infratentorial microbleeds result from arteriolosclerotic angiopathy, whereas strictly lobar microbleeds are caused by cerebral amyloid angiopathy [96].

The high prevalence of cerebral microbleeds and their potential link with bleeding-prone microangiopathy raised our interest in how these relate to antithrombotic drug use. We found that persons who had used or were using antithrombotic medication more often have cerebral microbleeds [97, 98]. Moreover, we found that the use of oral anticoagulants is associated with a higher incidence of microbleeds [99]. With regard to consequences of microbleeds, we found that the presence and amount of microbleeds increases the risk of stroke and mortality [100, 101]. Especially microbleeds in locations suggestive of amyloid angiopathy increase the risk of cerebral hemorrhages [101]. In addition, we found that microbleeds are 
associated with the progression of ischemic small vessel disease and loss of white matter structural integrity [102, 103]. Finally, we also showed that the presence of numerous microbleeds, especially in a strictly lobar location, is associated with worse cognitive performance. Adjustment for vascular risk factors and other imaging markers of small vessel disease did not alter this association [104], suggesting an independent role for microbleedassociated vasculopathy in cognitive impairment.

\section{Cerebral blood flow}

Total cerebral blood flow (tCBF) and total brain perfusion (tCBF per $100 \mathrm{ml}$ brain tissue) were measured with 2D phase contrast imaging as described above. We showed a close relationship between tCBF and markers of the microvasculature, e.g. retinal vessel diameters [75]. In 892 persons aged 60 years and older, we further showed that determinants of tCBF and total brain perfusion differ largely, due to the large influence of brain volume on tCBF values [105]. In a longitudinal study, we further investigated the relation between brain volume and $\mathrm{tCBF}$, and our results indicate that brain atrophy likely causes the tCBF to decrease over time, rather than vice versa [106].

When investigating determinants of $\mathrm{tCBF}$, we found that pulse pressure, body mass index, current smoking, and kidney function importantly contribute to variations in $\mathrm{tCBF}$ $[105,107]$. Furthermore, persons with low total brain perfusion had significantly more WMLs compared to those with high total brain perfusion. The role of tCBF with cognitive performance appeared more complex with brain atrophy either confounding or mediating the association [108]. Finally, we found that the parenchymal CBF is higher is persons with migraine during the attack-free period when compared with persons without migraine, supporting the idea of sustained vascular differences in migraineurs [109].

\section{White matter microstructural integrity}

We demonstrated that age-related changes in the normalappearing white matter are primarily but not exclusively explained by white matter atrophy and formation of WMLs [110]. Using tract-specific analyses, we found specific white matter tracts including the commissural and limbic tracts, to be most prominently affected by aging. Furthermore, we found that white matter atrophy and WML formation related to loss of integrity in distinct brain regions, indicating that the two processes are not sequential events but are rather independent and thus pathophysiologically potentially different [53]. Finally, we found that white matter changes can already be quantified using DTI and FLAIR before actual WML develop. This suggests that WML develop gradually and that the WMLs that are visible only represent a small portion of the underlying white matter pathology [111].

We demonstrated that besides traditional cardiovascular risk factors [110], intracranial carotid artery atherosclerosis [87], cerebral microbleeds [102], and a reduced kidney function [112], are all associated with loss of white matter microstructural integrity.

We have found DTI parameters within WMLs and normal-appearing white matter to be associated with cognitive function, even when taking into account volume of WMLs and white matter atrophy [52]. This indicates that the deleterious effect of white matter changes on cognition not only depends on lesion burden or amount of atrophy, but also on characteristics that are not easily evaluated by conventional MRI.

\section{Imaging genetics}

Since the advent of genome-wide association studies (GWAS) we have been involved in numerous studies in which the underlying genetics of various brain traits are investigated [113]. We have for example contributed to the identification of several single nucleotide polymorphisms (SNPs) associated with intracranial volume [114], and subcortical brain structures [115]. In collaboration with research partners in the CHARGE consortium [116], we performed a genome-wide association study of WML burden and were able to identify 6 risk-associated SNPs on chromosome 17q25 [117], which we subsequently replicated in a separate Rotterdam Scan Study cohort [41]. More recently, we identified another set of novel genetic loci implicating inflammation and glial proliferation in the development of WML [118]. Similar analyses have been undertaken for brain infarcts [119]. Moreover, we found that several risk variants of Alzheimer's disease and frontotemporal dementia are also associated with smaller total brain volume and hippocampal volume [120], and the volume of temporal brain regions [121].

For additional EJE references on determinants of common neurological disorders see [122-136].

\section{Incidental findings}

The large-scale acquisition of brain MRI comes with the detection of incidental findings [68]; abnormalities of potential clinical relevance unrelated to the purpose of the examination [137]. After scanning 2000 participants we found that the most frequent findings in the Rotterdam Scan Study are aneurysms (1.8\%) and benign primary tumors (meningiomas) (1.6\%) [68]. Currently, we are updating these numbers after scanning over 8500 participants, and evaluate the clinical management and natural 
course of these findings. This information may then serve as basis on which future recommendations for handling incidental findings in both the clinical setting and in research studies may be based.

For further EJE references on the handling of incidental findings in large-scale imaging studies see [138-141].

\section{Future perspectives}

The Rotterdam Scan Study provides a unique environment to study the etiology of neurological diseases in the elderly. Over 5800 persons have already undergone brain MRIscanning and in coming years repeated waves of follow-up examination will ensure a wealth of imaging data, especially from a longitudinal perspective. Until recently, the focus of our research has been mainly on the identification of risk factors and determinants of brain pathology. More recently, we have been examining the contribution of the various risk factors as discussed above and of novel risk factors with regard to the potential for prevention of stroke and dementia [142, 143]. In addition, we have also extended our scope of common neurological disorders to Parkinson's disease (for further EJE references on Parkinson's disease see [124, 144-149]), and for gait disorders see [92, 150-152]. In particular, our focus will include changes on brain imaging that relate to these conditions. Moreover, in the coming years, we plan to broaden our research in several ways, including the use of novel image sequences, novel post-processing techniques, and the identification of novel risk factors, and the mechanisms through which various lifestyle or genetic factors influence clinical outcomes through brain changes.

Currently, we are investigating the feasibility of adding perfusion imaging in the form of arterial spin labeling (ASL) to the scan protocol of the Rotterdam Scan Study. This will allow us to explore the interplay of structural and functional measures with (regional) brain perfusion. This is in particular of interest as perfusion may precede actual changes in structure or even function and could thus potentially be a very early marker of pathology.

Regarding new imaging markers, we are currently studying the prevalence and clinical correlates of small cortical brain infarcts in our population. In our initial report on these infarcts, we found that these are prevalent in $1.1 \%$ of the population and are associated with cardiovascular risk factors [70]. Our interest in these small cortical infarcts arose from the current attention for cortical microinfarcts-microscopic small infarcts seen on pathologic exams-as potential new markers of cerebrovascular disease and indicators of cognitive impairment. Though larger in size, the small cortical infarcts that can be identified on MRI may be reflecting pathology similar to these microscopic lesions and are therefore of interest for further research.

Another important focus of our research will be on functional connectivity as new imaging marker in neurodegenerative disease. Currently, we are finalizing the rsfMRI data analysis pipeline, and expect that end-2015 we will initiate the investigation of determinants and correlates of functional connectivity.

With regard to the MRI-scanner, we acknowledge that the ongoing hardware developments will necessitate upgrading of the scanner. Although there are no current plans to change the scanner, we foresee upgrading to a $3 \mathrm{~T}$ scanner in coming years.

Standardized and evaluated automated image processing techniques are crucial in exploiting the rich information that is available in population imaging data. They have enabled a transition from qualitative image interpretation into quantitative imaging. Quantitative imaging is nontrivial; it requires standardization and optimization in all the steps from data acquisition, to data analysis in structured reporting. In the next years, the number of validated quantitative image analysis techniques will further increase, also including more complex measures. Also, the results of these analyses will increasingly be stored in a standardized manner. This will enable a richer characterization of brain anatomy, pathology, connectivity and function. Relating these quantitative image measures to disease status, progression and events, will be a powerful tool for development of novel diagnostic and prognostic quantitative imaging biomarkers.

The standardization of image acquisition and processing protocols also implies that high quality reference data are being acquired. We are working on a novel IT-infrastructure in which we use the various standardized analysis pipelines to create a well-defined library of imaging biomarkers. We foresee two main advantages of this strategy. First, this standardized and well-defined library of biomarker analyses may be used by other researchers. Second, the high quality data provide unique reference databases on numerous biomarkers, which may eventually serve as basis for use in a clinical setting to contrast findings in an individual with a reference population.

As already mentioned before, the concomitant continuous monitoring of all participants in the Rotterdam Study ensures that we have a wealth of clinical data available, including cognitive performance [125] and the occurrence of dementia and stroke. In the coming years we intend to expand our research on how MRI markers of brain pathology relate to these clinical outcomes. Finally, we intend to expand our (inter)national collaborations in the field of population-imaging and imaging genetics to further unravel the causes and consequences of neurological diseases in the elderly. 
Acknowledgments The authors thank all participants, technicians, and research staff of the Rotterdam Scan Study. We are also grateful to the general practitioners of the Ommoord area for their continued support. We thank Piotr Wielopolski, Henri Vrooman and Marius de Groot for their continued technical assistance during the study.

Funding The Rotterdam Scan Study is supported by the Erasmus MC University Medical Center, the Erasmus University Rotterdam, the Netherlands Organization for Scientific Research (NWO) Grant 918-46-615, the Netherlands Organization for Health Research and Development (ZonMW), the Research Institute for Disease in the Elderly (RIDE), and the European Union Seventh Framework Programme (FP7/2007-2013) under grant agreement No. 601055, VPHDARE@IT, the Dutch Technology Foundation STW (Perspectief programme: Population Imaging Genetics (Dr Niessen, Dr Ikram, Dr Vernooij). Dr. Ikram is further supported by the Netherlands Organisation for Health Research and Development (ZonMW Veni Grant 916.13.054), the Netherlands Heart Foundation (Grants 2009B102 and 2012T008), New Investigator Research Grant from the Alzheimer Association (2014-NIRG-305710), MRace grant Erasmus MC 2011, Erasmus MC Fellowship 2013, Biobanking and Biomolecular Research Infrastructure (BBMRI) Grant CP2013-67, Internationale Stichting Alzheimer Onderzoek Grant 12533, and Stichting ParkinsonFonds. Dr. Vernooij is supported by a clinical fellowship (ZonMW Grant 90700453), Alzheimer Nederland (Grant WE03.2012-030). Prof. van der Lugt is supported by the Alzheimers Association (Grant NIRG-08-91391). Further support was obtained from General Electric Health Care.

Open Access This article is distributed under the terms of the Creative Commons Attribution 4.0 International License (http://crea tivecommons.org/licenses/by/4.0/), which permits unrestricted use, distribution, and reproduction in any medium, provided you give appropriate credit to the original author(s) and the source, provide a link to the Creative Commons license, and indicate if changes were made.

\section{References}

1. Hachinski V. Stroke and Alzheimer disease: fellow travelers or partners in crime? Arch Neurol. 2011;68(6):797-8.

2. Seshadri S, Wolf PA, Beiser A, Au R, McNulty K, White R, et al. Lifetime risk of dementia and Alzheimer's disease. The impact of mortality on risk estimates in the Framingham Study. Neurology. 1997;49(6):1498-504.

3. Seshadri S, Wolf PA. Lifetime risk of stroke and dementia: current concepts, and estimates from the Framingham Study. Lancet Neurol. 2007;6(12):1106-14.

4. Thies W, Bleiler L. 2011 Alzheimer's disease facts and figures. Alzheimers Dement. 2011;7(2):208-44.

5. Meyer JS, Kawamura J, Terayama Y. White matter lesions in the elderly. J Neurol Sci. 1992;110(1-2):1-7.

6. Pantoni L, Leys D, Fazekas F, Longstreth WT Jr, Inzitari D, Wallin A, et al. Role of white matter lesions in cognitive impairment of vascular origin. Alzheimer Dis Assoc Disord. 1999;13(Suppl 3):S49-54.

7. Fazekas F, Niederkorn K, Schmidt R, Offenbacher H, Horner S, Bertha $G$, et al. White matter signal abnormalities in normal individuals: correlation with carotid ultrasonography, cerebral blood flow measurements, and cerebrovascular risk factors. Stroke. 1988;19(10):1285-8.

8. Hachinski VC. The decline and resurgence of vascular dementia. CMAJ. 1990;142(2):107-11.
9. Fazekas F, Kleinert R, Offenbacher H, Schmidt R, Kleinert G, Payer F, et al. Pathologic correlates of incidental MRI white matter signal hyperintensities. Neurology. 1993;43(9):1683-9.

10. Pantoni L, Garcia JH. Pathogenesis of leukoaraiosis: a review. Stroke. 1997;28(3):652-9.

11. DeCarli C, Massaro J, Harvey D, Hald J, Tullberg M, Au R, et al. Measures of brain morphology and infarction in the framingham heart study: establishing what is normal. Neurobiol Aging. 2005;26(4):491-510.

12. de Groot JC, de Leeuw FE, Oudkerk M, Hofman A, Jolles J, Breteler MM. Cerebral white matter lesions and subjective cognitive dysfunction: the Rotterdam Scan Study. Neurology. 2001;56(11):1539-45.

13. Launer LJ, Oudkerk M, Nilsson LG, Alperovitch A, Berger K, Breteler MM, et al. CASCADE: a European collaborative study on vascular determinants of brain lesions. Study design and objectives. Neuroepidemiology. 2000;19(3):113-20.

14. Launer LJ. Epidemiology of white-matter lesions. Int Psychogeriatr. 2003;15(Suppl 1):99-103.

15. Launer LJ. Epidemiology of white matter lesions. Top Magn Reson Imaging. 2004;15(6):365-7.

16. Massaro JM, D’Agostino RB Sr, Sullivan LM, Beiser A, DeCarli $\mathrm{C}, \mathrm{Au} \mathrm{R}$, et al. Managing and analysing data from a largescale study on Framingham Offspring relating brain structure to cognitive function. Stat Med. 2004;23(2):351-67.

17. Schmidt R, Fazekas F, Offenbacher H, Lytwyn H, Blematl B, Niederkorn K, et al. Magnetic resonance imaging white matter lesions and cognitive impairment in hypertensive individuals. Arch Neurol. 1991;48(4):417-20.

18. Schmidt R, Fazekas F, Kapeller P, Schmidt H, Hartung HP. MRI white matter hyperintensities: three-year follow-up of the Austrian Stroke Prevention Study. Neurology. 1999;53(1):132-9.

19. de Leeuw FE, de Groot JC, Achten E, Oudkerk M, Ramos LM, Heijboer R, et al. Prevalence of cerebral white matter lesions in elderly people: a population based magnetic resonance imaging study. The Rotterdam Scan Study. J Neurol Neurosurg Psychiatry. 2001;70(1):9-14.

20. Ikram MA, van der Lugt A, Niessen WJ, Krestin GP, Koudstaal PJ, Hofman A, et al. The Rotterdam Scan Study: design and update up to 2012. Eur J Epidemiol. 2011;26(10):811-24.

21. Hofman A, Brusselle GG, Darwish Murad S, van Duijn CM, Franco OH, Goedegebure A, et al. The Rotterdam Study: 2016 objectives and design update. Eur J Epidemiol. 2015;30(8):661-708.

22. Jones DK, Simmons A, Williams SC, Horsfield MA. Non-invasive assessment of axonal fiber connectivity in the human brain via diffusion tensor MRI. Magn Reson Med. 1999;42(1):37-41.

23. Jones DK, Horsfield MA, Simmons A. Optimal strategies for measuring diffusion in anisotropic systems by magnetic resonance imaging. Magn Reson Med. 1999;42(3):515-25.

24. Buijs PC, Krabbe-Hartkamp MJ, Bakker CJ, de Lange EE, Ramos LM, Breteler MM, et al. Effect of age on cerebral blood flow: measurement with ungated two-dimensional phase-contrast MR angiography in 250 adults. Radiology. 1998;209(3):667-74.

25. Klein S, Staring M, Pluim JP. Comparison of gradient approximation techniques for optimisation of mutual information in nonrigid registration. Proceedings of the SPIE medical imaging: image process; 2005

26. Sled JG, Zijdenbos AP, Evans AC. A nonparametric method for automatic correction of intensity nonuniformity in MRI data. IEEE Trans Med Imaging. 1998;17(1):87-97.

27. Anbeek P, Vincken KL, van Bochove GS, van Osch MJ, van der Grond J. Probabilistic segmentation of brain tissue in MR imaging. Neuroimage. 2005;27(4):795-804.

28. Blatter DD, Bigler ED, Gale SD, Johnson SC, Anderson CV, Burnett BM, et al. Quantitative volumetric analysis of brain MR: 
normative database spanning 5 decades of life. AJNR Am J Neuroradiol. 1995;16(2):241-51.

29. Cardenas VA, Ezekiel F, Di Sclafani V, Gomberg B, Fein G. Reliability of tissue volumes and their spatial distribution for segmented magnetic resonance images. Psychiatry Res. 2001;106(3):193-205.

30. Jernigan TL, Gamst AC. Changes in volume with age-consistency and interpretation of observed effects. Neurobiol Aging. 2005;26(9):1271-4; discussion 5-8.

31. Resnick SM, Pham DL, Kraut MA, Zonderman AB, Davatzikos C. Longitudinal magnetic resonance imaging studies of older adults: a shrinking brain. J Neurosci. 2003;23(8):3295-301.

32. Sowell ER, Peterson BS, Thompson PM, Welcome SE, Henkenius AL, Toga AW. Mapping cortical change across the human life span. Nat Neurosci. 2003;6(3):309-15.

33. Vrooman HA, Cocosco CA, van der Lijn F, Stokking R, Ikram MA, Vernooij MW, et al. Multi-spectral brain tissue segmentation using automatically trained k-Nearest-Neighbor classification. Neuroimage. 2007;37(1):71-81.

34. de Boer R, Vrooman HA, Ikram MA, Vernooij MW, Breteler MM, van der Lugt A, et al. Accuracy and reproducibility study of automatic MRI brain tissue segmentation methods. Neuroimage. 2010;51(3):1047-56.

35. Bokde AL, Teipel SJ, Schwarz R, Leinsinger G, Buerger K, Moeller T, et al. Reliable manual segmentation of the frontal, parietal, temporal, and occipital lobes on magnetic resonance images of healthy subjects. Brain Res Brain Res Protoc. 2005; 14(3): 135-45.

36. Bokde AL, Teipel SJ, Zebuhr Y, Leinsinger G, Gootjes L, Schwarz R, et al. A new rapid landmark-based regional MRI segmentation method of the brain. J Neurol Sci. 2002;194(1):35-40.

37. Ikram MA, Vernooij MW, Hofman A, Niessen WJ, van der Lugt A, Breteler MM. Kidney function is related to cerebral small vessel disease. Stroke. 2008;39(1):55-61.

38. Fischl B, Dale AM. Measuring the thickness of the human cerebral cortex from magnetic resonance images. Proc Natl Acad Sci USA. 2000;97(20):11050-5.

39. Dale AM, Fischl B, Sereno MI. Cortical surface-based analysis. I. Segmentation and surface reconstruction. Neuroimage. 1999;9(2):179-94.

40. de Boer R, Vrooman HA, van der Lijn F, Vernooij MW, Ikram MA, van der Lugt A, et al. White matter lesion extension to automatic brain tissue segmentation on MRI. Neuroimage. 2009;45(4):1151-61.

41. Verhaaren BF, de Boer R, Vernooij MW, Rivadeneira F, Uitterlinden AG, Hofman A, et al. Replication study of chr17q25 with cerebral white matter lesion volume. Stroke. 2011;42(11):3297-9.

42. Boykov Y, Veksler O, Zabih R. Fast approximate energy minimization via graph cuts. IEEE Trans Patt Anal Mach Intell. 2001;23(11):1222-39.

43. van der Lijn F, den Heijer T, Breteler MM, Niessen WJ. Hippocampus segmentation in MR images using atlas registration, voxel classification, and graph cuts. Neuroimage. 2008;43(4):708-20.

44. den Heijer T, Oudkerk M, Launer LJ, van Duijn CM, Hofman A, Breteler MM. Hippocampal, amygdalar, and global brain atrophy in different apolipoprotein E genotypes. Neurology. 2002;59(5):746-8.

45. den Heijer T, Tiemeier H, Luijendijk HJ, van der Lijn F, Koudstaal PJ, Hofman A, et al. A study of the bidirectional association between hippocampal volume on magnetic resonance imaging and depression in the elderly. Biol Psychiatry. 2011;70(2):191-7.

46. den Heijer T, van der Lijn F, Koudstaal PJ, Hofman A, van der Lugt A, Krestin GP, et al. A 10-year follow-up of hippocampal volume on magnetic resonance imaging in early dementia and cognitive decline. Brain. 2010;133(Pt 4):1163-72.

47. van der Lijn F, de Bruijne M, Klein S, den Heijer T, Hoogendam YY, van der Lugt A, et al. Automated brain structure segmentation based on atlas registration and appearance models. IEEE Trans Med Imaging. 2012;31(2):276-86.

48. van der Lijn F, Vernooij MW, Ikram MA, Vrooman H, Rueckert D, Hammers A et al. Automated localization of periventricular and subcortical white matter lesions. Progress in biomedical optics and imaging-SPIE; 2007.

49. van der Lijn F, de Bruijne M, Hoogendam YY, Klein S, Hameeteman R, Breteler MM et al. Cerebellum segmentation in MRI using atlas registration and local multi-scale image descriptors. Proceedings-2009 IEEE international symposium on biomedical imaging: from Nano to Macro; 2009.

50. Hoogendam YY, van der Geest JN, van der Lijn F, van der Lugt A, Niessen WJ, Krestin GP, et al. Determinants of cerebellar and cerebral volume in the general elderly population. Neurobiol Aging. 2012;33(12):2774-81.

51. Achterberg HC, van der Lijn F, den Heijer T, van der Lugt A, Breteler MM, Niessen WJ et al. Prediction of dementia by hippocampal shape analysis. Lecture Notes in Computer Sciences (including subseries Lecture Notes in Artificial Intelligence and Lecture Notes in Bioinformatics. 2010. p 42-9.

52. Vernooij MW, Ikram MA, Vrooman HA, Wielopolski PA, Krestin GP, Hofman A, et al. White matter microstructural integrity and cognitive function in a general elderly population. Arch Gen Psychiatry. 2009;66(5):545-53.

53. Vernooij MW, de Groot M, van der Lugt A, Ikram MA, Krestin GP, Hofman A, et al. White matter atrophy and lesion formation explain the loss of structural integrity of white matter in aging. Neuroimage. 2008;43(3):470-7.

54. Smith SM, Jenkinson M, Woolrich MW, Beckmann CF, Behrens TE, Johansen-Berg $\mathrm{H}$, et al. Advances in functional and structural MR image analysis and implementation as FSL. Neuroimage. 2004;23(Suppl 1):S208-19.

55. Smith SM, Jenkinson M, Johansen-Berg H, Rueckert D, Nichols TE, Mackay CE, et al. Tract-based spatial statistics: voxelwise analysis of multi-subject diffusion data. Neuroimage. 2006;31(4):1487-505.

56. Klein S, Staring M, Murphy K, Viergever MA, Pluim JP. elastix: a toolbox for intensity-based medical image registration. IEEE Trans Med Imaging. 2010;29(1):196-205.

57. Andersson JLR, Jenkinson M, Smith SM. Non-linear registration, aka spatial normalisation. FMRIB technical report TR07JA22010.

58. de Groot M, Vernooij MW, Klein S, Ikram MA, Vos FM, Smith SM, et al. Improving alignment in Tract-based spatial statistics: evaluation and optimization of image registration. Neuroimage. 2013;76:400-11.

59. de Boer R, Schaap M, van der Lijn F, Vrooman HA, de Groot M, van der Lugt A, et al. Statistical analysis of minimum cost path based structural brain connectivity. Neuroimage. 2011;55(2):557-65.

60. de Boer R, Schaap M, van der Lijn F, Vrooman HA, de Groot M, Vernooij MW, et al. Statistical analysis of structural brain connectivity. Med Image Comput Comput Assist Interv. 2010;13(Pt 2):101-8.

61. Fischl B, van der Kouwe A, Destrieux C, Halgren E, Segonne F, Salat $\mathrm{DH}$, et al. Automatically parcellating the human cerebral cortex. Cereb Cortex. 2004;14(1):11-22.

62. Fischl B, Salat DH, van der Kouwe AJ, Makris N, Segonne F, Quinn BT, et al. Sequence-independent segmentation of magnetic resonance images. Neuroimage. 2004;23(Suppl 1):S69-84.

63. Beckmann CF, Smith SM. Probabilistic independent component analysis for functional magnetic resonance imaging. IEEE Trans Med Imaging. 2004;23(2):137-52. 
64. Jenkinson M, Bannister P, Brady M, Smith S. Improved optimization for the robust and accurate linear registration and motion correction of brain images. Neuroimage. 2002;17(2):825-41.

65. Griffanti L, Salimi-Khorshidi G, Beckmann CF, Auerbach EJ, Douaud G, Sexton CE, et al. ICA-based artefact removal and accelerated fMRI acquisition for improved resting state network imaging. Neuroimage. 2014;95:232-47.

66. Salimi-Khorshidi G, Douaud G, Beckmann CF, Glasser MF, Griffanti L, Smith SM. Automatic denoising of functional MRI data: combining independent component analysis and hierarchical fusion of classifiers. Neuroimage. 2014;90:449-68.

67. Filippini N, MacIntosh BJ, Hough MG, Goodwin GM, Frisoni GB, Smith SM, et al. Distinct patterns of brain activity in young carriers of the APOE-epsilon4 allele. Proc Natl Acad Sci USA. 2009;106(17):7209-14.

68. Vernooij MW, Ikram MA, Tanghe HL, Vincent AJ, Hofman A, Krestin GP, et al. Incidental findings on brain MRI in the general population. N Engl J Med. 2007;357(18):1821-8.

69. Vernooij MW, Ikram MA, Hofman A, Krestin GP, Breteler MM, van der Lugt A. Superficial siderosis in the general population. Neurology. 2009;73(3):202-5.

70. Riba-Llena I, Koek M, Verhaaren BF, Vrooman HA, van der Lugt A, Hofman A, et al. Small cortical infarcts: prevalence, determinants, and cognitive correlates in the general population. Int J Stroke. 2015; doi:10.1111/ijs.12543.

71. Greenberg SM, Vernooij MW, Cordonnier C, Viswanathan A, AlShahi Salman R, Warach S, et al. Cerebral microbleeds: a guide to detection and interpretation. Lancet Neurol. 2009;8(2):165-74.

72. Vernooij MW, van der Lugt A, Ikram MA, Wielopolski PA, Niessen WJ, Hofman A, et al. Prevalence and risk factors of cerebral microbleeds: the Rotterdam Scan Study. Neurology. 2008;70(14):1208-14.

73. Adams HH, Cavalieri M, Verhaaren BF, Bos D, van der Lugt A, Enzinger C, et al. Rating method for dilated Virchow-Robin spaces on magnetic resonance imaging. Stroke. 2013;44(6):1732-5.

74. Adams HH, Hilal S, Schwingenschuh P, Wittfeld K, Van der Lee SJ, Decarli $\mathrm{C}$ et al. A Priori Collaboration in Population Imaging: the Uniform Neuro-Imaging of Virchow-Robin Spaces Enlargement (UNIVRSE) Consortium. Alzheimers Dement: Diagnosis, Assessment \& Disease; 2015. doi:10.1016/j.dadm. 2015.10.004.

75. de Jong FJ, Vernooij MW, Ikram MK, Ikram MA, Hofman A, Krestin GP, et al. Arteriolar oxygen saturation, cerebral blood flow, and retinal vessel diameters. The Rotterdam Study. Ophthalmology. 2008;115(5):887-92.

76. Ikram MA, van Oijen M, de Jong FJ, Kors JA, Koudstaal PJ, Hofman A, et al. Unrecognized myocardial infarction in relation to risk of dementia and cerebral small vessel disease. Stroke. 2008;39(5):1421-6.

77. Ikram MA, Vrooman HA, Vernooij MW, van der Lijn F, Hofman A, van der Lugt A, et al. Brain tissue volumes in the general elderly population. The Rotterdam Scan Study. Neurobiol Aging. 2008;29(6):882-90

78. Ikram MK, De Jong FJ, Van Dijk EJ, Prins ND, Hofman A, Breteler MM, et al. Retinal vessel diameters and cerebral small vessel disease: the Rotterdam Scan Study. Brain. 2006;129(Pt 1):182-8.

79. Ikram MK, Sim X, Jensen RA, Cotch MF, Hewitt AW, Ikram MA, et al. Four novel Loci (19q13, 6q24, 12q24, and 5q14) influence the microcirculation in vivo. PLoS Genet. 2010;6(10):e1001184.

80. van Dijk EJ, Breteler MM, Schmidt R, Berger K, Nilsson LG, Oudkerk $\mathrm{M}$, et al. The association between blood pressure, hypertension, and cerebral white matter lesions: cardiovascular determinants of dementia study. Hypertension. 2004;44(5):625-30.
81. van Dijk EJ, Prins ND, Vermeer SE, Vrooman HA, Hofman A, Koudstaal PJ, et al. C-reactive protein and cerebral small-vessel disease: the Rotterdam Scan Study. Circulation. 2005;112(6):900-5.

82. Verhaaren BF, Vernooij MW, de Boer R, Hofman A, Niessen WJ, van der Lugt A, et al. High blood pressure and cerebral white matter lesion progression in the general population. Hypertension. 2013;61(6):1354-9.

83. Vermeer SE, Den Heijer T, Koudstaal PJ, Oudkerk M, Hofman A, Breteler MM, et al. Incidence and risk factors of silent brain infarcts in the population-based Rotterdam Scan Study. Stroke. 2003;34(2):392-6.

84. Vermeer SE, Koudstaal PJ, Oudkerk M, Hofman A, Breteler MM. Prevalence and risk factors of silent brain infarcts in the population-based Rotterdam Scan Study. Stroke. 2002;33(1):21-5

85. van Velsen EF, Vernooij MW, Vrooman HA, van der Lugt A, Breteler MM, Hofman A, et al. Brain cortical thickness in the general elderly population: the Rotterdam Scan Study. Neurosci Lett. 2013;550:189-94.

86. Bos D, Ikram MA, Elias-Smale SE, Krestin GP, Hofman A, Witteman JC, et al. Calcification in major vessel beds relates to vascular brain disease. Arterioscler Thromb Vasc Biol. 2011;31(10):2331-7.

87. Bos D, Vernooij MW, Elias-Smale SE, Verhaaren BF, Vrooman HA, Hofman A, et al. Atherosclerotic calcification relates to cognitive function and to brain changes on magnetic resonance imaging. Alzheimers Dement. 2012;8(5 Suppl):S104-11.

88. Ikram MA, Vernooij MW, Vrooman HA, Hofman A, Breteler MM. Brain tissue volumes and small vessel disease in relation to the risk of mortality. Neurobiol Aging. 2009;30(3):450-6.

89. de Bruijn RF, Akoudad S, Cremers LG, Hofman A, Niessen WJ, van der Lugt A, et al. Determinants, MRI correlates, and prognosis of mild cognitive impairment: the Rotterdam Study. J Alzheimers Dis. 2014;42(Suppl 3):S239-49.

90. Ikram MA, Vrooman HA, Vernooij MW, den Heijer T, Hofman A, Niessen WJ, et al. Brain tissue volumes in relation to $\operatorname{cog}$ nitive function and risk of dementia. Neurobiol Aging. 2010;31(3):378-86.

91. Poels MM, Steyerberg EW, Wieberdink RG, Hofman A, Koudstaal PJ, Ikram MA, et al. Assessment of cerebral small vessel disease predicts individual stroke risk. J Neurol Neurosurg Psychiatry. 2012;83(12):1174-9.

92. Verlinden VJ, van der Geest JN, de Groot M, Hofman A, Niessen WJ, van der Lugt A et al. Structural and microstructural brain changes predict impairment in daily functioning. Am J Med. 2014;127(11):1089-96 e2.

93. Poels MM, Ikram MA, Vernooij MW. Improved MR imaging detection of cerebral microbleeds more accurately identifies persons with vasculopathy. AJNR Am J Neuroradiol. 2012;33(8):1553-6.

94. Poels MM, Vernooij MW, Ikram MA, Hofman A, Krestin GP, van der Lugt A, et al. Prevalence and risk factors of cerebral microbleeds: an update of the Rotterdam scan study. Stroke. 2010;41(10 Suppl):S103-6.

95. Poels MM, Ikram MA, van der Lugt A, Hofman A, Krestin GP, Breteler MM, et al. Incidence of cerebral microbleeds in the general population: the Rotterdam Scan Study. Stroke. 2011;42(3):656-61.

96. Mesker DJ, Poels MM, Ikram MA, Vernooij MW, Hofman A, Vrooman HA, et al. Lobar distribution of cerebral microbleeds: the Rotterdam Scan Study. Arch Neurol. 2011;68(5):656-9.

97. Vernooij MW, Haag MD, van der Lugt A, Hofman A, Krestin GP, Stricker BH, et al. Use of antithrombotic drugs and the presence of cerebral microbleeds: the Rotterdam Scan Study. Arch Neurol. 2009;66(6):714-20. 
98. Darweesh SK, Leening MJ, Akoudad S, Loth DW, Hofman A, Ikram MA, et al. Clopidogrel use is associated with an increased prevalence of cerebral microbleeds in a stroke-free population: the Rotterdam study. J Am Heart Assoc. 2013;2(5):e000359.

99. Akoudad S, Darweesh SK, Leening MJ, Koudstaal PJ, Hofman A, van der Lugt A, et al. Use of coumarin anticoagulants and cerebral microbleeds in the general population. Stroke. 2014;45(11):3436-9.

100. Akoudad S, Ikram MA, Koudstaal PJ, Hofman A, van der Lugt A, Vernooij MW. Cerebral microbleeds and the risk of mortality in the general population. Eur J Epidemiol. 2013;28(10):815-21.

101. Akoudad S, Portegies ML, Koudstaal PJ, Hofman A, van der Lugt A, Ikram MA, et al. Cerebral microbleeds are associated with an increased risk of stroke: the Rotterdam Study. Circulation. 2015;132(6):509-16.

102. Akoudad S, de Groot M, Koudstaal PJ, van der Lugt A, Niessen WJ, Hofman A, et al. Cerebral microbleeds are related to loss of white matter structural integrity. Neurology. 2013;81(22):1930-7.

103. Akoudad S, Ikram MA, Koudstaal PJ, Hofman A, Niessen WJ, Greenberg SM, et al. Cerebral microbleeds are associated with the progression of ischemic vascular lesions. Cerebrovasc Dis. 2014;37(5):382-8.

104. Poels MM, Ikram MA, van der Lugt A, Hofman A, Niessen WJ, Krestin GP, et al. Cerebral microbleeds are associated with worse cognitive function: the Rotterdam Scan Study. Neurology. 2012;78(5):326-33

105. Vernooij MW, van der Lugt A, Ikram MA, Wielopolski PA, Vrooman HA, Hofman A, et al. Total cerebral blood flow and total brain perfusion in the general population: the Rotterdam Scan Study. J Cereb Blood Flow Metab. 2008;28(2):412-9.

106. Zonneveld HI, Loehrer EA, Hofman A, Niessen WJ, van der Lugt A, Krestin GP, et al. The bidirectional association between reduced cerebral blood flow and brain atrophy in the general population. J Cereb Blood Flow Metab. 2015;. doi:10.1038/ jcbfm.2015.157.

107. Sedaghat S, Vernooij MW, Loehrer E, Mattace-Raso FU, Hofman A, van der Lugt A, et al. Kidney function and cerebral blood flow: The Rotterdam Study. J Am Soc Nephrol. 2015; doi:10.1681/ASN.2014111118.

108. Poels MM, Ikram MA, Vernooij MW, Krestin GP, Hofman A, Niessen WJ, et al. Total cerebral blood flow in relation to cognitive function: the Rotterdam Scan Study. J Cereb Blood Flow Metab. 2008;28(10):1652-5.

109. Loehrer E, Vernooij MW, van der Lugt A, Hofman A, Ikram MA. Migraine and cerebral blood flow in the general population. Cephalalgia. 2015;35(2):190-8.

110. de Groot M, Ikram MA, Akoudad S, Krestin GP, Hofman A, van der Lugt A, et al. Tract-specific white matter degeneration in aging: the Rotterdam Study. Alzheimers Dement. 2015;11(3):321-30.

111. de Groot M, Verhaaren BF, de Boer R, Klein S, Hofman A, van der Lugt A, et al. Changes in normal-appearing white matter precede development of white matter lesions. Stroke. 2013;44(4):1037-42.

112. Sedaghat S, Cremers LG, de Groot M, Hoorn EJ, Hofman A, van der Lugt A, et al. Kidney function and microstructural integrity of brain white matter. Neurology. 2015;85(2):154-61.

113. Ikram MA, DeCarli C. Next frontiers in the genetic epidemiology of Alzheimer's disease. Eur J Epidemiol. 2012;27(11):831-6

114. Ikram MA, Fornage M, Smith AV, Seshadri S, Schmidt R, Debette $\mathrm{S}$, et al. Common variants at $6 \mathrm{q} 22$ and $17 \mathrm{q} 21$ are associated with intracranial volume. Nat Genet. 2012;44(5):539-44.

115. Hibar DP, Stein JL, Renteria ME, Arias-Vasquez A, Desrivieres $\mathrm{S}$, Jahanshad $\mathrm{N}$, et al. Common genetic variants influence human subcortical brain structures. Nature. 2015;520(7546):224-9.
116. Ikram MA, Seshadri S, Bis JC, Fornage M, DeStefano AL, Aulchenko YS, et al. Genomewide association studies of stroke. N Engl J Med. 2009;360(17):1718-28.

117. Fornage M, Debette S, Bis JC, Schmidt H, Ikram MA, Dufouil $\mathrm{C}$, et al. Genome-wide association studies of cerebral white matter lesion burden: the CHARGE consortium. Ann Neurol. 2011;69(6):928-39.

118. Verhaaren BF, Debette S, Bis JC, Smith JA, Ikram MK, Adams $\mathrm{HH}$, et al. Multiethnic genome-wide association study of cerebral white matter hyperintensities on MRI. Circ Cardiovasc Genet. 2015;8(2):398-409.

119. Debette S, Bis JC, Fornage M, Schmidt H, Ikram MA, Sigurdsson $\mathrm{S}$, et al. Genome-wide association studies of MRI-defined brain infarcts: meta-analysis from the CHARGE Consortium. Stroke. 2010;41(2):210-7.

120. Chauhan G, Adams HH, Bis JC, Weinstein G, Yu L, Toglhofer AM et al. Association of Alzheimer's disease GWAS loci with MRI markers of brain aging. Neurobiol Aging. 2015;36(4):1765 e7-16.

121. Adams HH, Verhaaren BF, Vrooman HA, Uitterlinden AG, Hofman A, van Duijn CM, et al. TMEM106B influences volume of left-sided temporal lobe and interhemispheric structures in the general population. Biol Psychiatry. 2014;76(6):503-8.

122. de Bruijn RF, Schrijvers EM, de Groot KA, Witteman JC, Hofman A, Franco OH, et al. The association between physical activity and dementia in an elderly population: the Rotterdam Study. Eur J Epidemiol. 2013;28(3):277-83.

123. Dufouil C, Pereira E, Chene G, Glymour MM, Alperovitch A, Saubusse E, et al. Older age at retirement is associated with decreased risk of dementia. Eur J Epidemiol. 2014;29(5):353-61.

124. Feldman AL, Wirdefeldt K, Johansson AL, Gatz M, Pedersen NL. Evidence for modest familial co-aggregation between dementia and parkinsonism. Eur J Epidemiol. 2014;29(1):49-56.

125. Hoogendam YY, Hofman A, van der Geest JN, van der Lugt A, Ikram MA. Patterns of cognitive function in aging: the Rotterdam Study. Eur J Epidemiol. 2014;29(2):133-40.

126. Jacqmin-Gadda H, Alperovitch A, Montlahuc C, Commenges D, Leffondre K, Dufouil C, et al. 20-Year prevalence projections for dementia and impact of preventive policy about risk factors. Eur J Epidemiol. 2013;28(6):493-502.

127. Marioni RE, Proust-Lima C, Amieva H, Brayne C, Matthews FE, Dartigues JF, et al. Cognitive lifestyle jointly predicts longitudinal cognitive decline and mortality risk. Eur J Epidemiol. 2014;29(3):211-9.

128. Mons U, Schottker B, Muller H, Kliegel M, Brenner H. History of lifetime smoking, smoking cessation and cognitive function in the elderly population. Eur J Epidemiol. 2013;28(10):823-31.

129. Novak M, Toren K, Lappas G, Kok WG, Jern C, Wilhelmsen L, et al. Occupational status and incidences of ischemic and hemorrhagic stroke in Swedish men: a population-based 35-year prospective follow-up study. Eur $J$ Epidemiol. 2013;28(8):697-704.

130. Palm F, Dos Santos M, Urbanek C, Greulich M, Zimmer K, Safer A, et al. Stroke seasonality associations with subtype, etiology and laboratory results in the Ludwigshafen Stroke Study (LuSSt). Eur J Epidemiol. 2013;28(5):373-81.

131. Pekmezovic T, Jovic J, Svetel M, Kostic VS. Prevalence of restless legs syndrome among adult population in a Serbian district: a community-based study. Eur $\mathrm{J}$ Epidemiol. 2013;28(11):927-30.

132. Skoog I. Is it dangerous or beneficial to drink coffee? Reflections on a meta-analysis on risk at birth and a population study on risk in late life. Eur J Epidemiol. 2014;29(10):665-6.

133. Virta JJ, Heikkila K, Perola M, Koskenvuo M, Raiha I, Rinne JO, et al. Midlife cardiovascular risk factors and late cognitive impairment. Eur J Epidemiol. 2013;28(5):405-16. 
134. Zhang Z, Xu G, Liu D, Zhu W, Fan X, Liu X. Dietary fiber consumption and risk of stroke. Eur $\mathrm{J}$ Epidemiol. 2013;28(2):119-30.

135. Lind L, Elmstahl S, Bergman E, Englund M, Lindberg E, Michaelsson K, et al. EpiHealth: a large population-based cohort study for investigation of gene-lifestyle interactions in the pathogenesis of common diseases. Eur $\mathrm{J}$ Epidemiol. 2013;28(2):189-97.

136. Nevalainen O, Raitanen J, Ansakorpi H, Artama M, Isojarvi J, Auvinen A. Long-term mortality risk by cause of death in newly diagnosed patients with epilepsy in Finland: a nationwide register-based study. Eur J Epidemiol. 2013;28(12):981-90.

137. Illes J, Kirschen MP, Edwards E, Stanford LR, Bandettini P, Cho MK, et al. Ethics. Incidental findings in brain imaging research. Science. 2006;311(5762):783-4.

138. Gondrie MJ, Mali WP, Buckens CF, Jacobs PC, Grobbee DE, van der Graaf Y. The PROgnostic Value of unrequested Information in Diagnostic Imaging (PROVIDI) Study: rationale and design. Eur J Epidemiol. 2010;25(10):751-8.

139. German National Cohort C. The German National Cohort: aims, study design and organization. Eur $\mathrm{J}$ Epidemiol. 2014;29(5):371-82.

140. de Mutsert R, den Heijer M, Rabelink TJ, Smit JW, Romijn JA, Jukema JW, et al. The Netherlands Epidemiology of Obesity (NEO) study: study design and data collection. Eur J Epidemiol. 2013;28(6):513-23.

141. White T, El Marroun H, Nijs I, Schmidt M, van der Lugt A, Wielopolki PA, et al. Pediatric population-based neuroimaging and the Generation R Study: the intersection of developmental neuroscience and epidemiology. Eur $\mathrm{J}$ Epidemiol. 2013;28(1):99-111.

142. Bos MJ, Koudstaal PJ, Hofman A, Ikram MA. Modifiable etiological factors and the burden of stroke from the Rotterdam study: a population-based cohort study. PLoS Med. 2014;11(4):e1001634.
143. de Bruijn RF, Bos MJ, Portegies ML, Hofman A, Franco OH, Koudstaal PJ, et al. The potential for prevention of dementia across two decades: the prospective, population-based Rotterdam Study. BMC Med. 2015;. doi:10.1186/s12916-015-0377-5.

144. Jiang W, Ju C, Jiang H, Zhang D. Dairy foods intake and risk of Parkinson's disease: a dose-response meta-analysis of prospective cohort studies. Eur J Epidemiol. 2014;29(9):613-9.

145. Kyrozis A, Ghika A, Stathopoulos P, Vassilopoulos D, Trichopoulos D, Trichopoulou A. Dietary and lifestyle variables in relation to incidence of Parkinson's disease in Greece. Eur J Epidemiol. 2013;28(1):67-77.

146. Mensikova K, Kanovsky P, Kaiserova M, Mikulicova L, Vastik $\mathrm{M}$, Hlustik $\mathrm{P}$, et al. Prevalence of neurodegenerative parkinsonism in an isolated population in south-eastern Moravia, Czech Republic. Eur J Epidemiol. 2013;28(10):833-6.

147. Schernhammer E, Qiu J, Wermuth L, Lassen CF, Friis S, Ritz B. Gout and the risk of Parkinson's disease in Denmark. Eur J Epidemiol. 2013;28(4):359-60.

148. Grant WB. The role of milk protein in increasing risk of Parkinson's disease. Eur J Epidemiol. 2013;28(4):357.

149. Lai SW, Liao KF, Lin CL, Sung FC. Irritable bowel syndrome correlates with increased risk of Parkinson's disease in Taiwan. Eur J Epidemiol. 2014;29(1):57-62.

150. Verlinden VJ, Maksimovic A, Mirza SS, Ikram MA, Kiefte-de Jong JC, Hofman A, et al. The associations of alcohol, coffee and tobacco consumption with gait in a community-dwelling population. Eur J Clin Nutr. 2015; doi:10.1038/ejen.2015.120.

151. Verlinden VJ, van der Geest JN, Heeringa J, Hofman A, Ikram MA. Gait shows a sex-specific pattern of associations with daily functioning in a community-dwelling population of older people. Gait Posture. 2015;41(1):119-24.

152. Verlinden VJ, van der Geest JN, Hofman A, Ikram MA. Cognition and gait show a distinct pattern of association in the general population. Alzheimers Dement. 2014;10(3):328-35. 